\title{
On the Nature of Electric Current in the Electrospinning Process
}

\author{
Baturalp Yalcinkaya, ${ }^{1}$ Fatma Yener, ${ }^{1}$ Oldrich Jirsak, ${ }^{1}$ and Funda Cengiz-Callioglu ${ }^{2}$ \\ ${ }^{1}$ Department of Nonwovens, Faculty of Textile Engineering, Technical University of Liberec, Studentska 2, 46117 Liberec, Czech Republic \\ ${ }^{2}$ Textile Engineering Department, Engineering Faculty, Suleyman Demirel University, Cunur, 32260 Isparta, Turkey
}

Correspondence should be addressed to Baturalp Yalcinkaya; baturalpyalcinkaya@hotmail.com

Received 8 July 2013; Accepted 23 October 2013

Academic Editor: Tong Lin

Copyright (C) 2013 Baturalp Yalcinkaya et al. This is an open access article distributed under the Creative Commons Attribution License, which permits unrestricted use, distribution, and reproduction in any medium, provided the original work is properly cited.

\begin{abstract}
The electric currents between electrodes in the electrospinning process are based on the movement of charge carriers through the spinning space. The majority of the charge carriers are formed by ionization of the air close to the metallic needle and to the polymer jet. The salt contained in the polymer solution contributes to the concentration of charge carriers, depending on its amount. The conductivity of polymer jets does not significantly affect the current since the jets do not link the electrodes.
\end{abstract}

\section{Introduction}

Electric current was studied across various electrospinning (ES) techniques, namely, in the needle ES [1-14], rod ES $[15,16]$, and roller ES [17]. In the needle ES, two sorts of experimental arrangement were employed: the "point-plate" geometry $[7,9,11]$ and "parallel-plate" geometry $[4,6,9,13]$. Advantages of the latter geometry are explained in [8]. It mainly consists of an easier interpretation of measured data in the uniform electric field of the parallel-plate spinner.

In the above mentioned works, the dependence of the electric current in the jet on various independent process parameters was studied, such as solution feed, solution conductivity, applied voltage, the diameter of the hollow needle, relative humidity, and some geometrical characteristics. The results of these experiments were formulated in a number of both phenomenological and theoretical equations, such as the dependence of the current in a jet on independent ES parameters [6], as shown in (1) and (2).

The empirical equation (1) says that the current was found to scale as

$$
I_{\text {total }} \approx E Q^{0.5} K^{0.4}
$$

where $I_{\text {total }}$ is the current flowing through a jet, $E$ is the field strength, $Q$ is the flow rate, and $K$ is the conductivity of the solution. Equation (1) may be applied to various polymer solutions in nonaqueous solvents. Theoretical Equation (2) describes current $I$ in a jet as

$$
I=\pi h^{2} K E+\frac{2 \sigma Q}{h},
$$

where $h$ is the radius of the jet, $K, Q$, and $E$ as in (1) above and $\sigma$ is the surface charge density.

The first term in (2) refers to the conduction current and the second to the advection of the surface charge.

It is the aim of the present work to study the dependence of current on various process parameters in more detail and to explain the results in terms of the mechanism of charge transport.

\section{Experimental}

In the experimental part, one preliminary test and four groups of experiments were performed as follows.

Preliminary Test. Measurement of changes in the current depending on the measuring device's needle protrusion length.

Group of Experiments 1. Measurement of changes in the current caused by polymer concentration, solution viscosity, solution conductivity, and voltage for both nonaqueous and aqueous polymer solutions. 


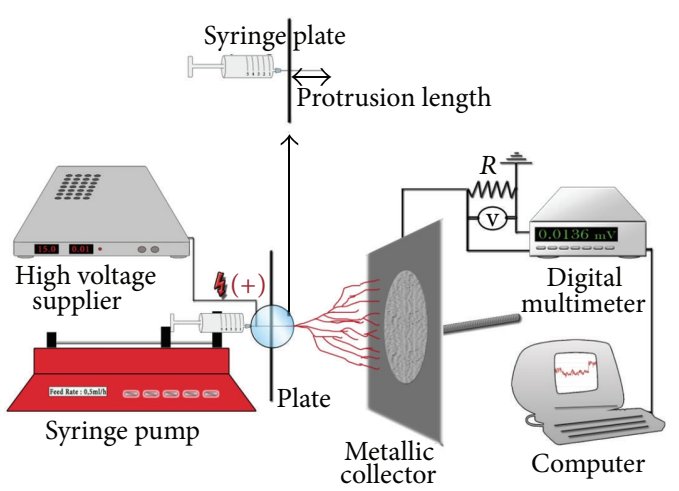

Figure 1: The "parallel-plate" spinner.

Because the results showed some discrepancies (see "Section 3"), additional experiments were performed to explain these discrepancies, as follows.

Group of Experiments 2. Measurement of jet length.

Group of Experiments 3. Measurement of the current in the "point-plate" and "parallel-plate" spinners using collectors of various sizes. These measurements were performed with and without polymer solutions.

Group of Experiments 4. Measurement of the current dependent on needle protrusion length, on jet length, and on their sum.

Two polymers and two solvents were used in these experiments to prepare a series of nonaqueous and aqueous solutions. It is known from previous works [6] that the nonaqueous and aqueous solutions show considerably different behaviour in the electrospinning process. The samples in both series differed in polymer concentration, viscosity, and conductivity as follows:

(1) polyurethane (PU), Larithane LS 1086 produced by Novotex, Italy, dimethylformamide (DMF), purchased from Fluka, and tetraethylammonium bromide (TEAB), purchased from Fluka;

(2) poly(ethylene oxide) (PEO), mol. weight 400,000 Da, purchased from Scientific Polymer Products, distilled water, and TEAB (as above).

The electric conductivity of the solutions was measured using a Radelkis OK-102/1 conductivity meter and the zeroshear viscosity was measured using a HAAKE Roto Visco rheometer at $25^{\circ} \mathrm{C}$. The list of samples, including their conductivities and viscosities, is shown in Table 1 through 4.

The solutions were electrospun in the "parallel-plate" spinner (Figure 1). The parallel plates were made of steel, with a diameter of $280 \mathrm{~mm}$. In a "parallel-plate" spinner, the needle penetrates through a small orifice in one plate. It is in contact with the plate so that the plate is charged to the same potential as the needle. The distance between the tip of the needle and the charged plate is called the "needle protrusion length."

In the preliminary test, the current was measured as a function of the protrusion length. The protrusion of the

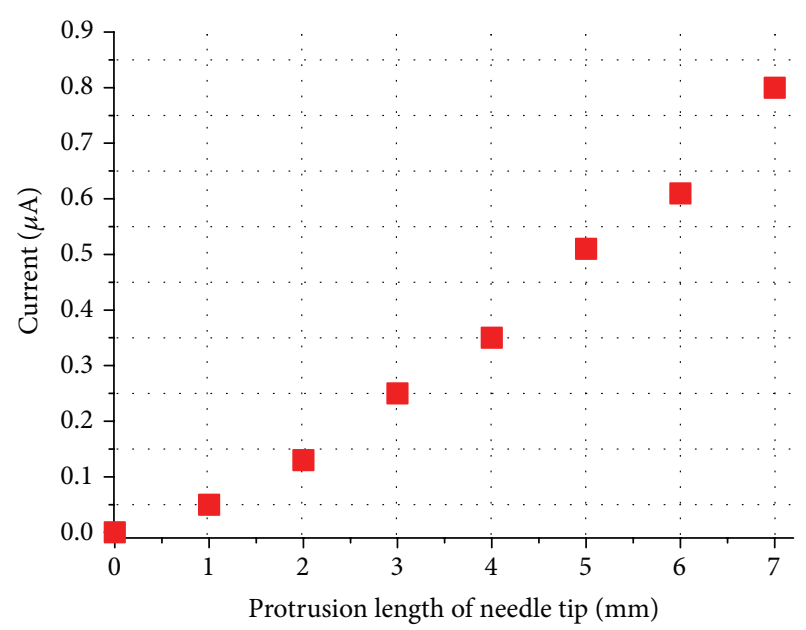

FIgURE 2: Dependence of the current on needle protrusion length in the "parallel-plate" spinner (the value of the current in the corresponding "point-plate" spinner, $20 \mu \mathrm{A}$, is not shown in Figure 2).

needle from the charged plate was mentioned by Shin et al. [4] and Fallahi et al. [10] as an important parameter of the spinner, and its effect on the current was found to be rather strong in the study of Shin et al. [4] and Yener et al. [17]. The dependence of the current on the protrusion length can be seen as a characteristic of the spinner. It was measured in the following conditions: polymer solution: $20 \% \mathrm{PU}$ in DMF + $1.27 \%$ TEAB, feed rate of $0.5 \mathrm{~mL} /$ hour, voltage of $35 \mathrm{kV}$, and a distance of $105 \mathrm{~mm}$ between the tip of the needle and the collector. During the experiment, the protrusion length was increased from 0 to $7 \mathrm{~mm}$ and the charged plate was then removed so that the device was converted from "parallelplate" to "point-plate" geometry. In "parallel-plate" geometry, the current grew with increasing protrusion length (Figure 2) from a value close to zero to ca. $0.7 \mu \mathrm{A}$. After the charged plate had been removed, the value of the current jumped to $20 \mu \mathrm{A}$ (not shown in Figure 2).

In the first group of experiments, the current was measured as a function of various independent parameters. The results are shown in Tables 4 and 5.

The spinning conditions were based on previous results so that nanofibers of a good quality were produced in all of the experiments: a protruding length of $7 \mathrm{~mm}$, an outer needle diameter of $0.6 \mathrm{~mm}$, and a feed rate of $0.5 \mathrm{~mL} /$ hour. Some other conditions, such as polymer concentrations and the distance between the tip of the needle and the collector plate, were different for PU and PEO solutions (see below). During the spinning process, the current was measured and the data were stored in a computer as described in [17].

In the second group of experiments, the length of the jets (Figure 3) was measured using the photographic records. A Sony Full HD NEX-VG10E Handy cam (14.2 megapixels)E18-200 mm Lens camera was used in the experiments. The results are shown in Tables 7 and 8.

In the third group of experiments, the current between the tip of the needle and the collector was measured as follows: 


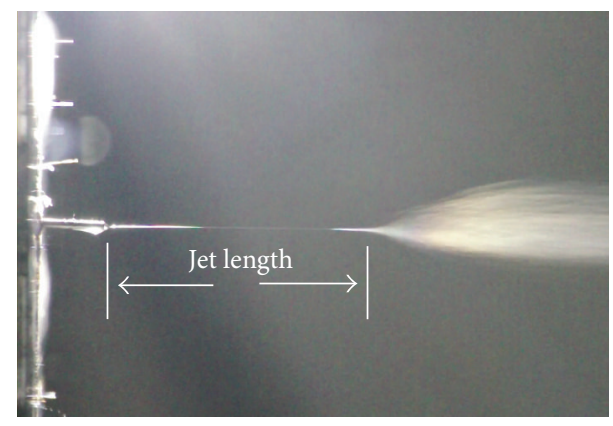

(a)

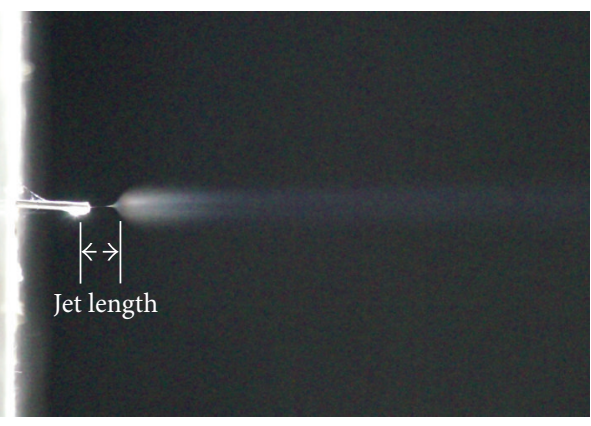

(b)

Figure 3: Photographic records of the polymer jet: (a) 20\% PU, $35 \mathrm{kV}$ and (b) $15 \% \mathrm{PU}+1.27 \% \mathrm{TEAB}, 35 \mathrm{kV}$.

(i) in both "parallel-plate" and "point plate" spinners,

(ii) with four collector electrodes differing from each other in size, namely,
(a) diameter of $280 \mathrm{~mm}$ (area $\left.61,600 \mathrm{~mm}^{2}\right)$,
(b) diameter of $80 \mathrm{~mm}$ (area $5,000 \mathrm{~mm}^{2}$ ),
(c) diameter of $10 \mathrm{~mm}\left(\right.$ area $\left.78.5 \mathrm{~mm}^{2}\right)$,
(d) diameter of $2.5 \mathrm{~mm}$ (area $4.9 \mathrm{~mm}^{2}$ ).

The experiments were variously carried out using the following:

(i) a low conductive solution (17.5\% PU, conductivity $0.04 \mathrm{mS} / \mathrm{cm}$ ),

(ii) a high conductive solution (17.5\% PU + 1.27\% TEAB, conductivity $1.6 \mathrm{mS} / \mathrm{cm}$ ),

(iii) no solution,

(iv) three different values of voltages being applied: 25 , 27.5 , and $30 \mathrm{kV}$,

(v) the distance from the tip of the needle to the collector being $105 \mathrm{~mm}$,

(vi) the solution feed being $0.5 \mathrm{~mL} /$ hour. 10.

The results of these experiments are shown in Tables 9 and

In the fourth group of experiments, the current was measured at various values of needle protrusion length. The length of jets was also measured as described above. The results are shown in Tables 11 and 12 and in Figures 7-11.

\section{Results and Discussion}

In the preliminary test, the dependence of the current on the "needle protrusion length" (Figure 2) was found to be rather strong. At the zero protrusion length, which can be understood as "pure" parallel-plate geometry, spinning hardly occurs and the current is close to zero. On the other hand, an extremely high protrusion length (represented by the pointplate geometry) exhibited currents as high as $20 \mu \mathrm{A}$. Thus, the dependence of the current on the "needle protrusion length" seems to be good characteristic of needle electrospinning devices.
TABLE 1: Samples of PU solutions and their conductivity.

\begin{tabular}{lcccc}
\hline $\begin{array}{l}\text { Concentration } \\
\text { of PU (\%) }\end{array}$ & \multicolumn{4}{c}{$\begin{array}{c}\text { Conductivity }(\mathrm{mS} / \mathrm{cm}) \\
\text { Concentration of TEAB (\%) }\end{array}$} \\
\hline 15 & 0 & 0.4 & 0.8 & 1.27 \\
17.5 & 0.046 & 0.672 & 1.188 & 1.72 \\
20 & 0.04 & 0.58 & 1.044 & 1.6 \\
\hline
\end{tabular}

TABLE 2: Samples of PU solutions and their zero-shear viscosity.

\begin{tabular}{lcccc}
\hline $\begin{array}{l}\text { Concentration } \\
\text { of PU (\%) }\end{array}$ & \multicolumn{4}{c}{ Viscosity (Pa.s) } \\
& 0 & 0.4 & 0.8 & 1.27 \\
\hline 15 & 0.493 & 0.492 & 0.514 & 0.536 \\
17.5 & 1.062 & 1.017 & 1.141 & 1.143 \\
20 & 2.159 & 2.354 & 2.599 & 2.642 \\
\hline
\end{tabular}

A list of the polymer solutions used in these experiments and their basic properties is shown in the following tables.

Tables 1 and 2 illustrate PU solutions in DMF containing $15,17.5$, and 20 weight percent of polymer and $0,0.4,0.8$, and 1.27 weight percent of TEAB. Tables $3(a)$ and $3(b)$ show PEO solutions in water containing $3,4,5$, and 6 weight per cent of polymer and 0 or 1 weight per cent of TEAB.

The data in Tables 1-3 shows anticipated facts, namely, the following:

(i) the conductivity of solutions grows with the salt content;

(ii) the conductivity of solutions containing salt falls when viscosity increases;

(iii) the viscosity of solutions increases with an increase in polymer concentration;

(iv) the viscosity of solutions is only moderately influenced by the salt content.

The results of the first group of experiments, the values of the current measured during the spinning at various levels of voltage are shown in Tables 4 and 5 . 
TABLE 3: Samples of PEO solutions and their conductivity and viscosity.

(a)

\begin{tabular}{lc}
\hline $\begin{array}{l}\text { Solutions }(\%) \\
\text { PEO + TEAB }\end{array}$ & $\begin{array}{c}\text { Conductivity } \\
(\mathrm{mS} / \mathrm{cm})\end{array}$ \\
\hline $3+0$ & 0.17 \\
$4+0$ & 0.18 \\
$5+0$ & 0.19 \\
$3+1$ & 4.88 \\
$4+1$ & 4.60 \\
$5+1$ & 4.28 \\
$6+1$ & 4.16 \\
\hline
\end{tabular}

(b)

\begin{tabular}{lc}
\hline Solutions (\%) & Viscosity $(\mathrm{Pa} \cdot \mathrm{s})$ \\
PEO + TEAB & 0.062 \\
\hline $3+0$ & 0.118 \\
$4+0$ & 0.233 \\
$5+0$ & 0.046 \\
$3+1$ & 0.117 \\
$4+1$ & 0.212 \\
$5+1$ & 0.332 \\
$6+1$ & \\
\hline
\end{tabular}

TABLE 4: Current during spinning of PU solutions. Distance between tip of needle and collector: $105 \mathrm{~mm}$.

\begin{tabular}{lccccc}
\hline Solutions (\%) & \multicolumn{5}{c}{ Current $(\mu \mathrm{A})$} \\
PU + TEAB & 25 & 27.5 & 30 & 32.5 & 35 \\
\hline $15+0$ & 0 & 0.039 & 0.081 & 0.11 & 0.14 \\
$15+0.4$ & 0.025 & 0.071 & 0.11 & 0.13 & 0.22 \\
$15+0.8$ & 0.050 & 0.076 & 0.12 & 0.20 & 0.30 \\
$15+1.27$ & 0.12 & 0.21 & 0.33 & 0.48 & 0.55 \\
\hline $17.5+0$ & 0.019 & 0.061 & 0.11 & 0.13 & 0.18 \\
$17.5+0.4$ & 0.089 & 0.13 & 0.20 & 0.33 & 0.42 \\
$17.5+0.8$ & 0.10 & 0.17 & 0.22 & 0.40 & 0.56 \\
$17.5+1.27$ & 0.15 & 0.22 & 0.39 & 0.56 & 0.79 \\
\hline $20+0$ & 0.025 & 0.091 & 0.13 & 0.16 & 0.20 \\
$20+0.4$ & 0.10 & 0.16 & 0.23 & 0.36 & 0.53 \\
$20+0.8$ & 0.11 & 0.19 & 0.29 & 0.41 & 0.76 \\
$20+1.27$ & 0.17 & 0.27 & 0.42 & 0.69 & 0.91 \\
\hline
\end{tabular}

Note that the electrospinning process and the current between electrodes can be influenced by the electric resistance of the electrospun nanofiber layer and/or take-up fabric depending on their thickness and resistivity. The presented experiments have been conducted in a relatively short time; therefore, the resistances were negligible.

The values of the currents in Tables 4 and 5 show some unexpected relationships (a)-(c) as follows.
TABLE 5: Current during spinning of PEO solutions. Distance between tip of needle and collector: $150 \mathrm{~mm}$.

\begin{tabular}{lccccc}
\hline \multirow{2}{*}{$\begin{array}{c}\text { Solutions (\%) } \\
\text { PEO + TEAB }\end{array}$} & \multicolumn{5}{c}{ Current $(\mu \mathrm{A})$} \\
& 25 & 27.5 & 30 & 32.5 & 35 \\
\hline $3+0$ & 0.38 & 0.55 & 0.72 & 0.92 & 1.33 \\
$4+0$ & 0.21 & 0.29 & 0.43 & 0.51 & 0.66 \\
$5+0$ & 0.15 & 0.25 & 0.35 & 0.44 & 0.59 \\
\hline $3+1$ & 1.28 & 1.63 & 1.80 & 2.26 & 2.57 \\
$4+1$ & 1.57 & 1.76 & 2.14 & 2.46 & 2.70 \\
$5+1$ & 1.73 & 2.00 & 2.38 & 2.68 & 3.03 \\
$6+1$ & 1.87 & 2.30 & 2.62 & 3.13 & 3.86 \\
\hline
\end{tabular}

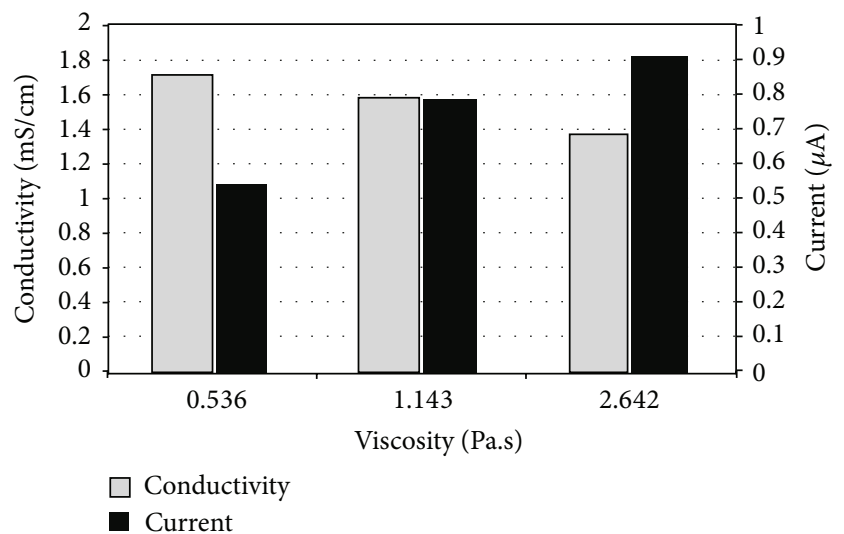

FIGURE 4: Dependence of solution conductivity and measured current in ES on solution viscosity. Solutions: PU 15, 17.5, and 20\%, all containing $1.27 \%$ of TEAB.

(a) The electric conductivity of all solutions containing salt decreases as viscosity/polymer concentration increases. This is easy to explain given the lower mobility of ions in more viscous solutions. In contrast, the current measured during the ES process grew with increasing viscosity. This was observed at all the values of voltage and salt content (in the PU solutions), in both the aqueous and nonaqueous solutions, and is in conflict with (1) and (2).

To make the situation more comprehensible for readers, Figure 4 gives a representation of the unexpected relations.

(b) The growth of the measured current in proportion to the applied voltage is much steeper than that predicted by (1) and (2).

(c) The calculation of the current from (2) yields much larger values than those measured experimentally.

Since it is difficult to estimate the surface charge density $\sigma$ in (2), we have calculated the current from the first part of (2) only as follows:

$$
I=\pi h^{2} K E .
$$


TABLE 6: Values of current (in $\mu \mathrm{S}$ ) calculated from (3).

\begin{tabular}{lccc}
\hline $\begin{array}{l}\text { Conductivity } \\
\text { of solution } \\
(\mathrm{mS} / \mathrm{cm})\end{array}$ & \multicolumn{3}{c}{$\begin{array}{c}\text { Current }(\mu \mathrm{A}) \\
\text { Jet diameter } 2 \mathrm{~h}(\mathrm{~mm})\end{array}$} \\
\hline 0.05 & 98 & 0.2 & 0.1 \\
0.1 & 196 & 15.7 & 3.92 \\
0.2 & 392 & 31.4 & 7.85 \\
0.5 & 980 & 62.8 & 15.7 \\
1 & 1960 & 314 & 39.2 \\
5 & 9800 & 1570 & 78.5 \\
\hline
\end{tabular}

TABLE 7: Length of jets, polyurethane solutions.

\begin{tabular}{lccccc}
\hline $\begin{array}{l}\text { Solutions (\%) } \\
\text { PU + TEAB }\end{array}$ & \multicolumn{5}{c}{ Jet length $(\mathrm{mm})$} \\
& 25 & 27.5 & 30 & 32.5 & 35 \\
\hline $15+0$ & & 3.69 & 5.11 & 5.60 & 6.15 \\
$15+0.4$ & 1.55 & 1.51 & 1.52 & 1.76 & 1.99 \\
$15+0.8$ & 1.30 & 1.43 & 1.32 & 1.50 & 1.67 \\
$15+1.27$ & 1.00 & 1.10 & 1.27 & 1.30 & 1.56 \\
$17.5+0$ & 4.63 & 5.45 & 7.16 & 13.46 & 15.68 \\
$17.5+0.4$ & 3.07 & 2.74 & 2.69 & 2.58 & 3.60 \\
$17.5+0.8$ & 2.81 & 2.67 & 2.60 & 2.62 & 2.68 \\
$17.5+1.27$ & 3.02 & 2.82 & 2.80 & 2.27 & 2.68 \\
$20+0$ & 5.90 & 8.08 & 8.13 & 15.67 & 18.42 \\
$20+0.4$ & 3.30 & 3.01 & 3.48 & 3.50 & 4.14 \\
$20+0.8$ & 3.08 & 2.95 & 2.73 & 2.67 & 3.45 \\
$20+1.27$ & 3.30 & 2.95 & 2.90 & 2.77 & 2.98 \\
\hline
\end{tabular}

TABLE 8: Length of jets, PEO solutions.

\begin{tabular}{lccccc}
\hline \multirow{2}{*}{$\begin{array}{c}\text { Solutions (\%) } \\
\text { PEO + TEAB }\end{array}$} & \multicolumn{5}{c}{ Jet length $(\mathrm{mm})$} \\
& 25 & 27.5 & 30 & 32.5 & 35 \\
\hline $3+0$ & 21.32 & 22.33 & 22.32 & 22.31 & 21.29 \\
$4+0$ & 26.55 & 28.04 & 30.67 & 28.75 & 35.00 \\
$5+0$ & 51.36 & 54.38 & 54.81 & 51.92 & 57.47 \\
$3+1$ & 20.14 & 19.75 & 22.46 & 17.71 & 20.98 \\
$4+1$ & 22.51 & 21.63 & 21.36 & 20.94 & 22.18 \\
$5+1$ & 32.79 & 30.99 & 33.88 & 38.92 & 32.20 \\
$6+1$ & 35.24 & 34.67 & 37.54 & 40.30 & 39.42 \\
\hline
\end{tabular}

For this calculation, the jets were approximated by a cylinder of diameter $2 h$. According to the data in the literature [8] as well as to our own measurements, the jet diameter can be estimated as being between 0.1 and $0.5 \mathrm{~mm}$. Therefore, the current was calculated for jet diameters of $0.1,0.2$, and $0.5 \mathrm{~mm}$.

The conductivities of the solutions were chosen as follows: $0.05,0.1,0.5,1$, and $5 \mathrm{mS} / \mathrm{cm}$; these were chosen to correspond to the values in Tables 1 and 3. A value of $100000 \mathrm{~V} / \mathrm{m}$ was

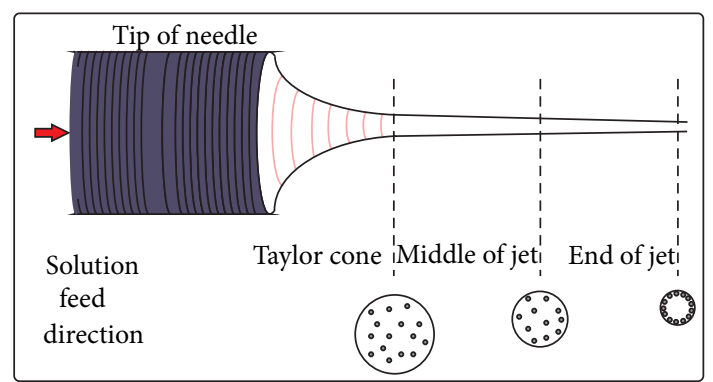

FIGURE 5: Radial movement of ions in a jet.

given for $E$. The calculated values of the current are shown in Table 6.

The values of the current in Table 6 are significantly larger than the experimental values, corresponding to solutions of similar conductivities in Tables 4 and 5. The difference amounts to approximately 3 decimal orders.

Further measurements carried out within the second group of experiments were inspired by the Ph.D. thesis of Dao [18], who measured the length of jets and their dependence on various spinning parameters, the viscosity of polymer solutions, among others. The results of the measurements are given in Tables 7 and 8 .

The results in Tables 7 and 8 can be summarized as follows:

(i) very short $(1 \mathrm{~mm})$ as well as very long $(60 \mathrm{~mm})$ jets were observed and the measurements are well reproducible;

(ii) the length of the jets does not depend on the applied voltage except in cases of very low salt content or low conductivity (observed at PU only);

(iii) the length of the jets decreases with increased salt content (observed at PU, but not measured at PEO);

(iv) the length of the jets significantly increases with growing solution viscosity.

Dao [18] offered the following interpretation of the above dependencies: in the polymer solutions, ions are randomly distributed in bulk. In the jet, due to repulsive forces, ions move radially toward the jet surface. The velocity of the movement is limited by the solution's viscosity. When the concentration of ions at the jet surface reaches a critical value, the jet is converted into nanofibers via whipping instability and/or splitting. Thus, low viscosity and high salt content help to create critical ions concentration in less time, which leads to shorter jets (shown in Figure 5). Nevertheless, neither Dao's theory nor the presented experiments offer an explanation for the substantial difference between the PU and PEO jet lengths.

Let us go back now to unexpected relationships (a)(c) mentioned previously. Two attempts have been made to explain the measured data.

The first attempt was based on the model shown in Figure 6. In the model, the space between the tip of the needle and the collector electrode consists of two sub-spaces, 


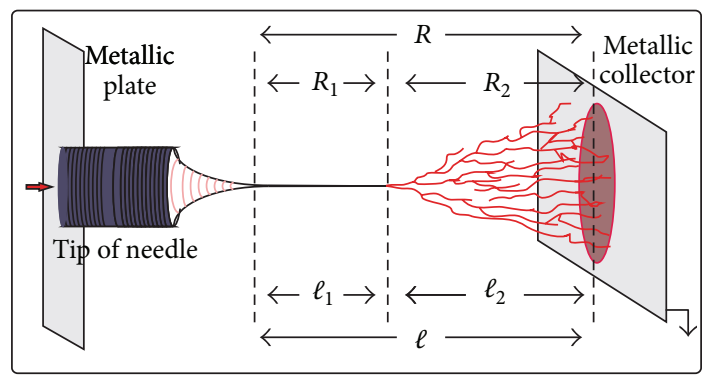

FIGURE 6: Model of spinning space.

namely, of jet subspace and fibers subspace. The size of the space is expressed as

$$
\ell=\ell_{1}+\ell_{2},
$$

where $\ell_{1}$ is the length of the jet sub-space and $\ell_{2}$ is the length of the fibers sub-space. Electric resistance of the space is found by the following equation:

$$
R=R_{1}+R_{2}=\rho_{1} \ell_{1}+\rho_{2} \ell_{2},
$$

where $\rho_{1}$ and $\rho_{2}$ are resistivities in $\left(\Omega \mathrm{m}^{-1}\right)$ of both sub-spaces. Let us suppose that resistivity $\rho_{1}$ depends on the conductivity and diameter of the jet according to (3). The resistivity of the fiber sub-space $\rho_{2}$ is connected to the transport of charges with polymer fibers, salt molecules, and ions, evaporated solvent, and plasma particles created in the strong electric field and is probably much greater than $\rho_{1}$. Therefore, longer jets lead to shorter $\ell_{2}$, smaller $R_{2}$, smaller total resistance $R$, and a greater current.

The total resistance $R$ was calculated using Ohm's law and $R_{1}$ from the solution conductivity, length, and diameter of the jet. The same jet diameters of $0.2 \mathrm{~mm}$ were used in the calculations for all of the jets and then, the values of $R_{2}, \rho_{1}$, and $\rho_{2}$ were calculated using (4) and (5).

An example of calculation is as follows.

Data: voltage $U=10^{4} \mathrm{~V}$, current $I=1 \mu \mathrm{A}$, solution conductivity $K=1 \mathrm{mScm}^{-1}=0.1 \mathrm{Sm}^{-1}, l=100 \mathrm{~mm}$, $l_{1}=10 \mathrm{~mm}, l_{2}=90 \mathrm{~mm}$, and jet radius $h=0.1 \mathrm{~mm}$.

Then, one has the following:

total conduction of spinning space $R=U / I=10^{10} \Omega$, conduction of the jet $K_{1}=K \times \pi h^{2} / l_{1}=\pi \times 10^{-7} \mathrm{~S}$, resistance of the jet $R_{1}=1 / K_{1}=3.2 \times 10^{6} \Omega$,

resistance of fiber space $R_{2}=R-R_{1}=0.99968 \times$ $10^{10} \Omega$,

resistivities: $\rho_{1}=3.2 \times 10^{8} \Omega \mathrm{m}^{-1}, \rho_{2}=1.111 \times$ $10^{11} \Omega \mathrm{m}^{-1}$.

The calculations did not support the model in Figure 6. The following results were observed.

(i) The resistances $R_{2}$ amounted to $3-200 \times 10^{9} \mathrm{Ohms}$ for the sample solutions taken into experiments. Compared to that, the calculated jet resistances $R_{1}$ were
TABLE 9: Current $(\mu \mathrm{A})$ in the "parallel-plate" spinner.

\begin{tabular}{lcccc}
\hline Solutions & $\begin{array}{c}\text { Collector diameter } \\
(\mathrm{mm})\end{array}$ & \multicolumn{3}{c}{ Current $(\mu \mathrm{A})$} \\
& 280 & 25 & 27.5 & 30 \\
\hline & 80 & 0 & 0 & 0 \\
No solution & 10 & 0 & 0 & 0 \\
& 2.5 & 0 & 0 & 0 \\
\hline Low conducting & 280 & 0.019 & 0.061 & 0.110 \\
$17.5 \% \mathrm{PU}$ & 80 & 0.014 & 0.041 & 0.072 \\
$0.04 \mathrm{mS} / \mathrm{cm}$ & 10 & 0.009 & 0.032 & 0.054 \\
& 2.5 & 0 & 0.648 & 2.035 \\
\hline High conducting & 280 & 0.150 & 0.222 & 0.395 \\
$17.5 \% \mathrm{PU}+1.27 \%$ & 80 & 0.106 & 0.174 & 0.334 \\
TEAB & 10 & 0.070 & 0.119 & 0.297 \\
$1.6 \mathrm{mS} / \mathrm{cm}$ & 2.5 & 1.613 & 2.359 & 3.126 \\
\hline
\end{tabular}

found to be 4 to 6 decimal orders smaller $(0.2-4 \times$ $10^{6} \mathrm{Ohms}$ ) so that total resistance $R$ is almost equal to $R_{1}$. This also justifies the use of a single value for the jet diameter $-0.2 \mathrm{~mm}-$ in the calculations: the values of $R_{2}$ would be almost the same if the diameter was plus or minus one decimal order.

(ii) The values of $\rho_{1}$ and $\rho_{2}$ were expected to be constant in the groups of solutions containing the same polymer and equal concentration of salt. As the calculations revealed, this was not the case. The differences in total resistances (and current) cannot be explained by different lengths of relatively high conductive jets.

In the second attempt to explain the above discrepancies, the role of plasma particles was studied. The plasma particles generated by the ionization of air in a strong electric field move between electrodes (through both jet sub-space and fibers sub-space as seen in Figure 6) and serve as charge carriers, contributing to the total electric current. Plasma particles can be formed at the collector electrode if it is small enough as well as at the tip of the needle and the polymer jet, depending on the needle protrusion length and jet length. To evaluate the effect of plasma particles, the third and fourth group of experiments were performed.

The third group of experiments consisted of spinning, using collector electrodes of various diameters. The parameters of the experiments are described in the experimental section. The results are shown in Tables 9 and 10 .

The results in Tables 9 and 10 show the following.

(i) The values of the current are considerably larger in the "point-plate" spinner than in the "parallel-plate" spinner. This is due to the high intensity of the electric field at the tip of the needle, which leads to the formation of additional plasma particles as charge carriers.

(ii) In the "parallel-plate" spinner, plasma particles are formed with the collector of the smallest diameter 
TABLE 10: Current $(\mu \mathrm{A})$ in the "point-plate" spinner.

\begin{tabular}{lcccc}
\hline \multirow{2}{*}{ Solutions } & $\begin{array}{c}\text { Collector diameter } \\
(\mathrm{mm})\end{array}$ & \multicolumn{3}{c}{ Current $(\mu \mathrm{A})$} \\
& & 25 & 27.5 & 30 \\
\hline & 280 & 5.40 & 7.33 & 8.86 \\
No solution & 80 & 5.19 & 7.15 & 8.61 \\
& 10 & 2.03 & 2.54 & 3.46 \\
& 2.5 & 8.63 & 12.02 & 16.30 \\
\hline \multirow{2}{*}{ Low conducting } & 280 & 7.04 & 10.40 & 15.52 \\
$17.5 \% \mathrm{PU}$ & 80 & 4.94 & 6.94 & 8.05 \\
$0.04 \mathrm{mS} / \mathrm{cm}$ & 10 & 2.71 & 3.48 & 4.71 \\
& 2.5 & 5.53 & 6.92 & 11.85 \\
\hline High conducting & 280 & 7.79 & 12.63 & 16.59 \\
$17.5 \% \mathrm{PU}+1.27 \%$ & 80 & 5.53 & 6.97 & 9.08 \\
TEAB & 10 & 3.25 & 4.14 & 8.77 \\
$1.6 \mathrm{mS} / \mathrm{cm}$ & 2.5 & 8.75 & 12.06 & 15.34 \\
\hline
\end{tabular}

TABLE 11: Dependence of the current on needle protrusion length and jet length in PU solutions.

\begin{tabular}{|c|c|c|c|c|}
\hline $\begin{array}{l}\text { Solutions (\%) } \\
\text { PU + TEAB }\end{array}$ & $\begin{array}{l}\text { Protrusion } \\
\text { length } \\
(\mathrm{mm})\end{array}$ & $\begin{array}{c}\text { Jet } \\
\text { length } \\
(\mathrm{mm})\end{array}$ & $\begin{array}{c}\text { Protrusion } \\
\text { length } \\
+ \\
\text { jet length } \\
(\mathrm{mm})\end{array}$ & $\begin{array}{c}\text { Average } \\
\text { current } \\
(\mu \mathrm{A})\end{array}$ \\
\hline \multirow{7}{*}{$15+1.27$} & 0 & 0 & 0 & 0 \\
\hline & 2 & 0 & 2 & 0 \\
\hline & 4 & 1.62 & 5.62 & 0.101 \\
\hline & 6 & 1.43 & 7.43 & 0.255 \\
\hline & 8 & 1.29 & 9.29 & 0.763 \\
\hline & 10 & 1.22 & 11.22 & 1.117 \\
\hline & 12 & 0.98 & 12.98 & 1.452 \\
\hline \multirow{7}{*}{$17.5+1.27$} & 0 & 0 & 0 & 0 \\
\hline & 2 & 5.02 & 7.02 & 0.113 \\
\hline & 4 & 4.17 & 8.17 & 0.295 \\
\hline & 6 & 2.91 & 8.91 & 0.573 \\
\hline & 8 & 2.92 & 10.92 & 1.019 \\
\hline & 10 & 2.95 & 12.95 & 1.418 \\
\hline & 12 & 2.81 & 14.81 & 1.667 \\
\hline \multirow{7}{*}{$20+1.27$} & 0 & 0 & 0 & 0 \\
\hline & 2 & 5.71 & 7.71 & 0.226 \\
\hline & 4 & 4.36 & 8.36 & 0.444 \\
\hline & 6 & 3.08 & 9.08 & 0.718 \\
\hline & 8 & 3.11 & 11.11 & 1.172 \\
\hline & 10 & 3.01 & 13.01 & 1.561 \\
\hline & 12 & 3.01 & 15.01 & 1.840 \\
\hline
\end{tabular}

$(2.5 \mathrm{~mm})$ only. This yields the highest values of current when compared with the other collectors. The smallest collector increases current even in the "point-plate" spinner.
TABLE 12: Dependence of the current on needle protrusion length and jet length in PEO solutions.

\begin{tabular}{|c|c|c|c|c|}
\hline $\begin{array}{l}\text { Solutions (\%) } \\
\text { PEO + TEAB }\end{array}$ & $\begin{array}{c}\text { Protrusion } \\
\text { length } \\
(\mathrm{mm})\end{array}$ & $\begin{array}{c}\text { Jet } \\
\text { length } \\
(\mathrm{mm})\end{array}$ & $\begin{array}{c}\text { Protrusion } \\
\text { length } \\
+ \\
\text { jet length } \\
(\mathrm{mm})\end{array}$ & $\begin{array}{c}\text { Average } \\
\text { current } \\
(\mu \mathrm{A})\end{array}$ \\
\hline \multirow{7}{*}{$3+1$} & 0 & 0 & 0 & 0 \\
\hline & 2 & 22.38 & 24.38 & 0.582 \\
\hline & 4 & 21.56 & 25.56 & 0.611 \\
\hline & 6 & 20.15 & 26.15 & 1.668 \\
\hline & 8 & 19.23 & 27.23 & 2.104 \\
\hline & 10 & 17.88 & 27.88 & 2.445 \\
\hline & 12 & 17.51 & 29.51 & 3.240 \\
\hline \multirow{7}{*}{$4+1$} & 0 & 0 & 0 & 0 \\
\hline & 2 & 31.76 & 33.76 & 0.558 \\
\hline & 4 & 30.54 & 34.54 & 1.391 \\
\hline & 6 & 29.12 & 35.12 & 1.913 \\
\hline & 8 & 27.37 & 35.37 & 2.310 \\
\hline & 10 & 26.23 & 36.23 & 2.874 \\
\hline & 12 & 24.43 & 36.43 & 3.859 \\
\hline \multirow{7}{*}{$5+1$} & 0 & 0 & 0 & 0 \\
\hline & 2 & 37.83 & 39.83 & 0.682 \\
\hline & 4 & 36.94 & 40.94 & 1.732 \\
\hline & 6 & 36.91 & 42.91 & 2.069 \\
\hline & 8 & 36.22 & 44.22 & 2.586 \\
\hline & 10 & 35.47 & 45.47 & 3.279 \\
\hline & 12 & 33.99 & 45.99 & 4.130 \\
\hline \multirow{7}{*}{$6+1$} & 0 & 0 & 0 & 0 \\
\hline & 2 & 47.29 & 49.29 & 1.375 \\
\hline & 4 & 46.42 & 50.42 & 2.140 \\
\hline & 6 & 45.88 & 51.88 & 2.590 \\
\hline & 8 & 45.84 & 53.84 & 3.045 \\
\hline & 10 & 44.37 & 54.37 & 3.672 \\
\hline & 12 & 42.83 & 54.83 & 4.566 \\
\hline
\end{tabular}

(iii) Plasma particles are not formed at collectors with $10 \mathrm{~mm}$ diameters and larger.

(iv) With these larger collectors, the current increases with the increasing collector diameter due to the increased area for charge carriers to move in the cone between the needle tip and collector. Thus, a greater collector diameter makes the resistance $R_{2}$ smaller.

The process of the air ionization and formation of plasma particles in the strong electric field has been studied and described by many authors [19-22]. To explain the role of needle protrusion length and jet length in forming plasma particles, current and length of jets were measured in the fourth group of experiments. Needle protrusion length was an independent parameter in the experiments.

Note: it is obvious from Tables 11 and 12 that an increase in the needle protrusion length leads to a shorter jet length. This 


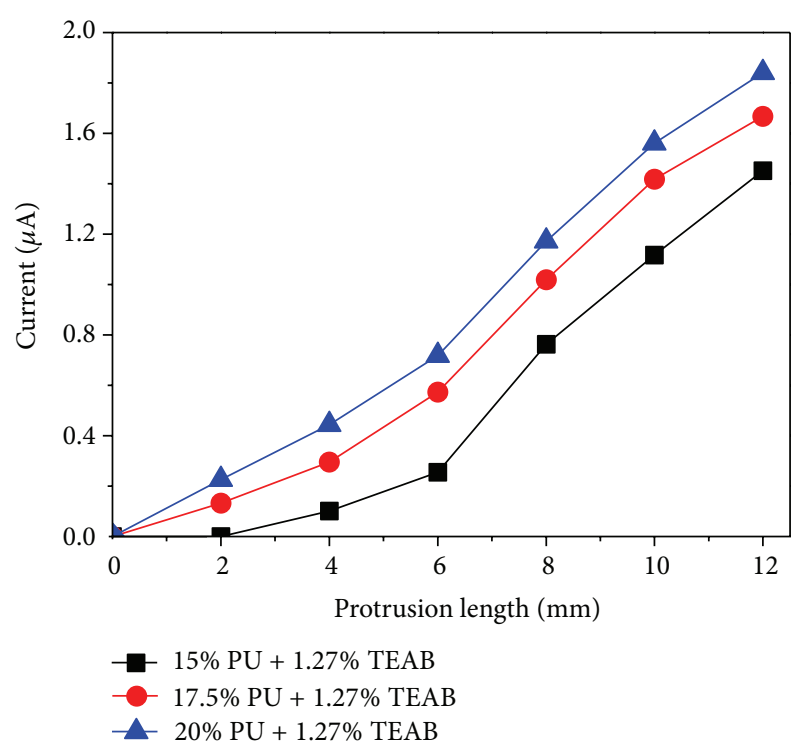

FIGURE 7: Dependence of current on needle protrusion length in PU solutions.

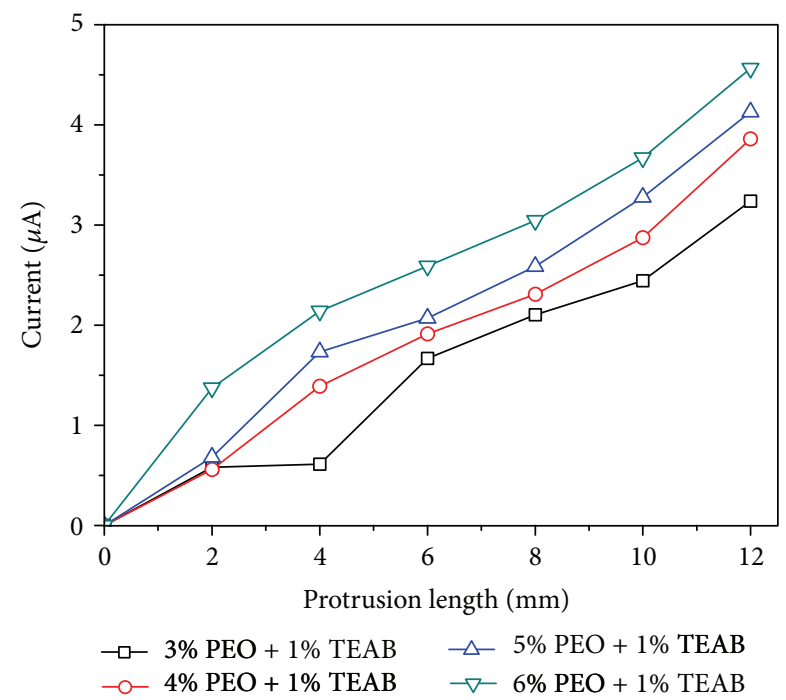

Figure 8: Dependence of current on needle protrusion length in PEO solutions.

is caused by the deformation of the electric field in the vicinity of highly conductive needle and resultant smaller elongation of the jet.

The results, shown in Tables 11 and 12 and in Figures 7 and 8 , indicate that both needle protrusion length and jet length contribute to an increase in the current. Therefore, the current is plotted against the sum of the protruding length and the jet length in Figures 9 and 10.

The graphs in Figures 9 and 10 show significant differences in the behaviour between PU and PEO solutions. PU solutions create short $(1-6 \mathrm{~mm})$ jets and the current depends on the sum of the protrusion length and the jet length. Conversely, PEO solutions create much longer (17-48 mm)

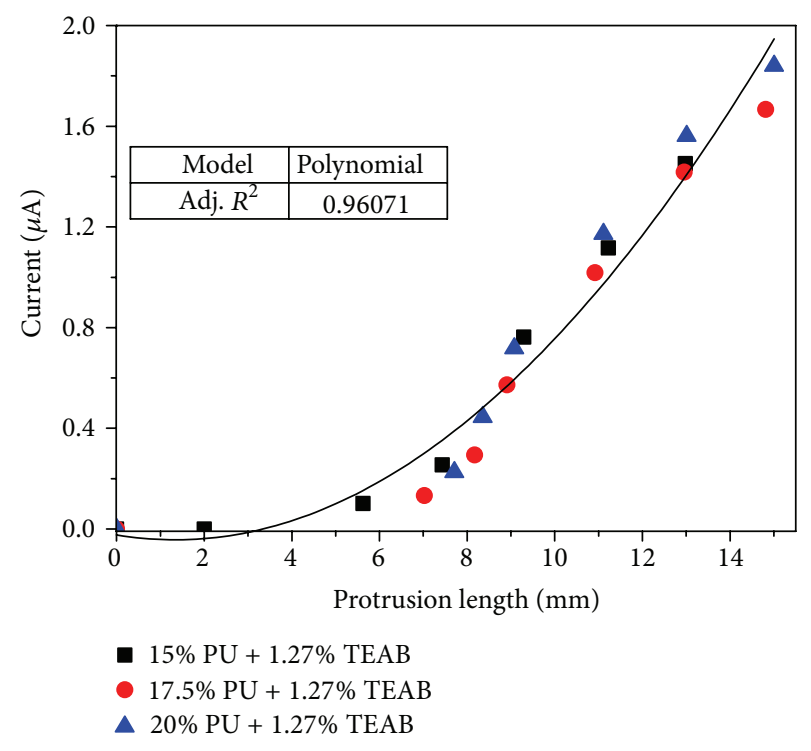

Figure 9: Dependence of current on the sum of needle protrusion length and jet length in PU solutions.

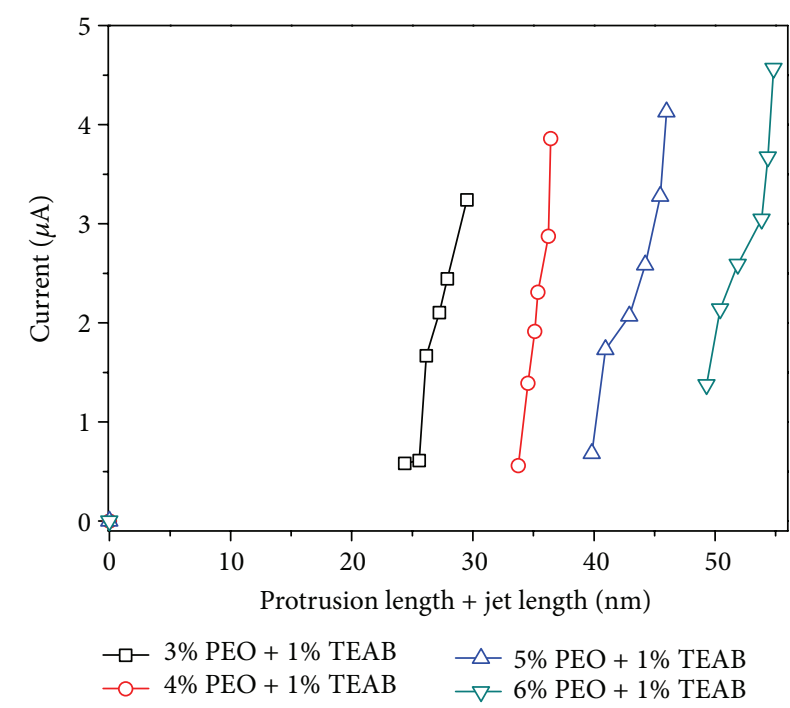

FIgURE 10: Dependence of current on the sum of needle protrusion length and jet length in PEO solutions.

jets, and the effect of the jet length on the formation of plasma particles is less than that of the needle protrusion length.

To evaluate the role of jet length in PEO solutions relative to that of needle protrusion length, the current was plotted against the value of the protrusion length $+(N \times$ jet length $)$. The optimum value of coefficient $N=0.16$ was found based on the correlation coefficient in the polynomial model for the above relation-see Figure 11.

\section{Conclusions}

The results of the experiments show that the value of the electric current in the electrospinning process is mainly based 


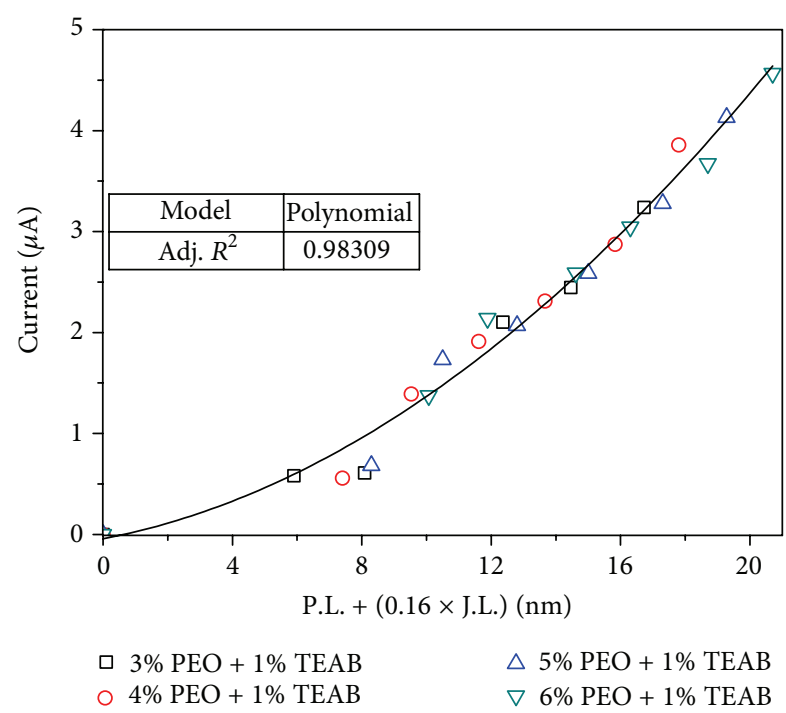

FIGURE 11: Dependence of current on protrusion length $+(N \times$ jet length), $N=0.16$ in PEO solutions.

on the movement of charge carriers between the spinning and collector electrodes. The charge carriers are mainly formed by the ionization of air in the vicinity of small objects, such as the protruding part of the needle, a jet, or a collector electrode, provided it is small enough. The number of charge carriers depends on the strength of the electric field, that is, on the voltage applied and the size of electrodes. The salts contained in polymer solutions are another source of charge carriers. Nevertheless, the plasma particles formed by the ionization of air are the dominant source of charge carriers. As the data in Table 10 show, a rather strong current can be observed between the electrodes even without any feed of polymer solution. Charge carriers move between the electrodes through the "sub-spaces" shown in Figure 6. Thus, the idea of the total resistance of spinning space $R$ as a sum of $R_{1}$ and $R_{2}$ is not relevant to the explanation of the nature of the electric current.

The plasma particles moving between the electrodes create the effect known as "electric wind." This effect can be stopped by a sheet of paper.

Equation (1), describing the experimentally found dependence of current on $E, Q$, and $K$, is in agreement with our experiments: increasing $E$ enhances the ionization process considerably, while increasing $Q$ and $K$ is linked with greater amounts of salts as a source of charge carriers.

On the other hand, (2) describes the conductivity of the jet itself, which has no relation to the total current measured during the electrospinning process.

\section{Future Work}

Further research may be conducted on some particular points, including the following:

(i) the effect of specific polymers, solvents, and salts on the length of jets; (ii) the effect of the same variables on the ionization of air;

(iii) the effect of jet length on the ionization of air and so forth;

(iv) the effect of environmental conditions on the current.

\section{Acknowledgment}

The authors are thankful for the Ministry of Education, Youth, and Sports of the Czech Republic (student's grant competition TUL in specific university research in 2012, Project no. 4866, and 2013, Project no. 48004) for their financial support.

\section{References}

[1] M. M. Hohman, M. Shin, G. Rutledge, and M. P. Brenner, "Electrospinning and electrically forced jets. I. Stability theory," Physics of Fluids, vol. 13, no. 8, pp. 2201-2220, 2001.

[2] M. M. Hohman, M. Shin, G. Rutledge, and M. P. Brenner, "Electrospinning and electrically forced jets. II. Applications," Physics of Fluids, vol. 13, no. 8, pp. 2221-2236, 2001.

[3] Y. M. Shin, M. M. Hohman, M. P. Brenner, and G. C. Rutledge, "Electrospinning: a whipping fluid jet generates submicron polymer fibers," Applied Physics Letters, vol. 78, no. 8, pp. 11491151, 2001.

[4] Y. M. Shin, M. M. Hohman, M. P. Brenner, and G. C. Rutledge, "Experimental characterization of electrospinning: the electrically forced jet and instabilities," Polymer, vol. 42, no. 25, pp. 9955-9967, 2001.

[5] S. J. Kim, C. K. Lee, and S. I. Kim, "Effect of ionic salts on the processing of poly(2-acrylamido-2-methyl-1- propane sulfonic acid) nanofibers," Journal of Applied Polymer Science, vol. 96, no. 4, pp. 1388-1393, 2005.

[6] P. K. Bhattacharjee, T. M. Schneider, M. P. Brenner, G. H. McKinley, and G. C. Rutledge, "On the measured current in electrospinning," Journal of Applied Physics, vol. 107, no. 4, Article ID 044306, pp. 1-8, 2010.

[7] J. M. Deitzel, J. Kleinmeyer, D. Harris, and N. C. B. Tan, "The effect of processing variables on the morphology of electrospun nanofibers and textiles," Polymer, vol. 42, no. 1, pp. 261-272, 2001.

[8] D. Fallahi, M. Rafizadeh, N. Mohammadi, and B. Vahidi, "Effects of feed rate and solution conductivity on jet current and fiber diameter in electrospinning of polyacrylonitrile solutions," E-Polymers, vol. 9, no. 1, pp. 1250-1257, 2013.

[9] R. Samatham and K. J. Kim, "Electric current as a control variable in the electrospinning process," Polymer Engineering \& Science, vol. 46, no. 7, pp. 954-959, 2006.

[10] D. Fallahi, M. Rafizadeh, N. Mohammadi, and B. Vahidi, "Effect of applied voltage on jet electric current and flow rate in electrospinning of polyacrylonitirile solutions," Polymer International, vol. 57, no. 12, pp. 1363-1368, 2008.

[11] M. M. Demir, I. Yilgor, E. Yilgor, and B. Erman, "Electrospinning of polyurethane fibers," Polymer, vol. 43, no. 11, pp. 33033309,2002

[12] S. A. Theron, E. Zussman, and A. L. Yarin, "Experimental investigation of the governing parameters in the electrospinning of polymer solutions," Polymer, vol. 45, no. 6, pp. 2017-2030, 2004. 
[13] D. Fallahi, M. Rafizadeh, N. Mohammadi, and B. Vahidi, "Effect of applied voltage on surface and volume charge density of the jet in electrospinning of polyacrylonitrile solutions," Polymer Engineering \& Science, vol. 50, no. 7, pp. 1372-1376, 2010.

[14] M. M. Munir, F. Iskandar, K. Khairurrijal, and K. Okuyama, "A constant-current electrospinning system for production of high quality nanofibers," Review of Scientific Instruments, vol. 79, no. 9, Article ID 093904, 2008.

[15] P. Pokorny, P. Mikes, and D. Lukas, "Measurement of electric current in liquid jet," in Proceedings of the Nanocon Internatiol Conference, pp. 12-14, Olomouc, Czech Republic, October 2010.

[16] F. Cengiz-Callioglu, O. Jirsak, and M. Dayik, "Electric current in polymer solution jet and spinnability in the needleless electrospinning process," Fibers and Polymers, vol. 13, no. 10, pp. 1266-1271, 2012.

[17] F. Yener, B. Yalcinkaya, and O. Jirsak, "On the measured current in needle and needleless electrospinning," Journal of Nanoscience and Nanotechnology, vol. 13, no. 7, pp. 4672-4679, 2013.

[18] A. T. Dao, The role of rheological properties of polymer solutions in needleless electrostatic spinning [Ph.D. thesis], Department of Nonwovens, Technical University of Liberec, Liberec, Czech Republic, 2010.

[19] J. J. Lowke and R. Morrow, "Theory of electric corona including the role of plasma chemistry," Pure \& Applied Chemistry, vol. 66, no. 6, pp. 1287-1294, 1994.

[20] G. F. L. Ferreira, O. N. Oliveira Jr., and J. A. Giacometti, "Pointto-plane corona: current-voltage characteristics for positive and negative polarity with evidence of an electronic component," Journal of Applied Physics, vol. 59, no. 9, pp. 3045-3049, 1986.

[21] A. Jaworek and A. Krupa, "Corona discharge from a multipoint electrode in flowing air," Journal of Electrostatics, vol. 38, no. 3, pp. 187-197, 1996.

[22] V. E. Kalayci, P. K. Patra, Y. K. Kim, S. C. Ugbolue, and S. B. Warner, "Charge consequences in electrospun polyacrylonitrile (PAN) nanofibers," Polymer, vol. 46, no. 18, pp. 7191-7200, 2005. 

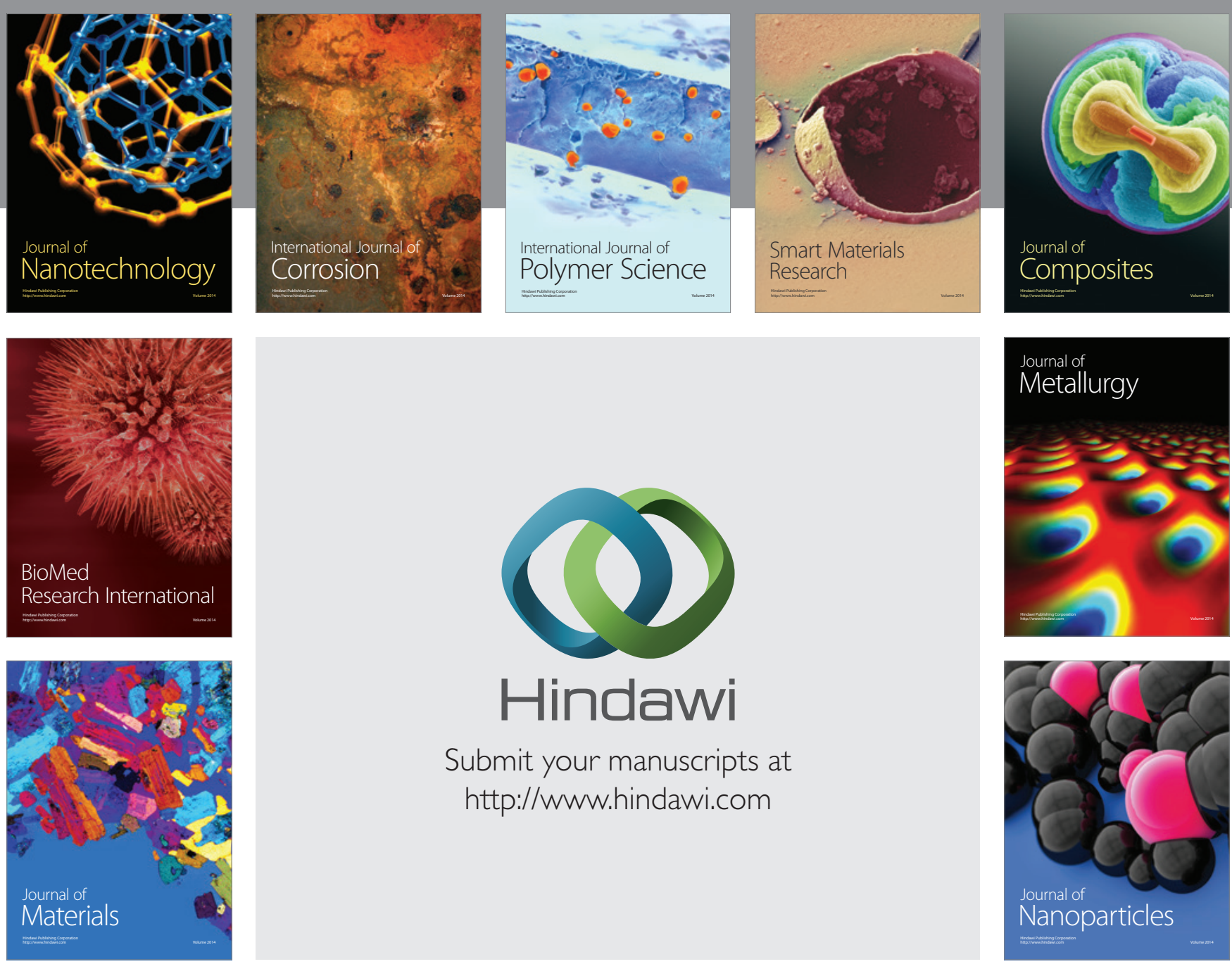

Submit your manuscripts at http://www.hindawi.com
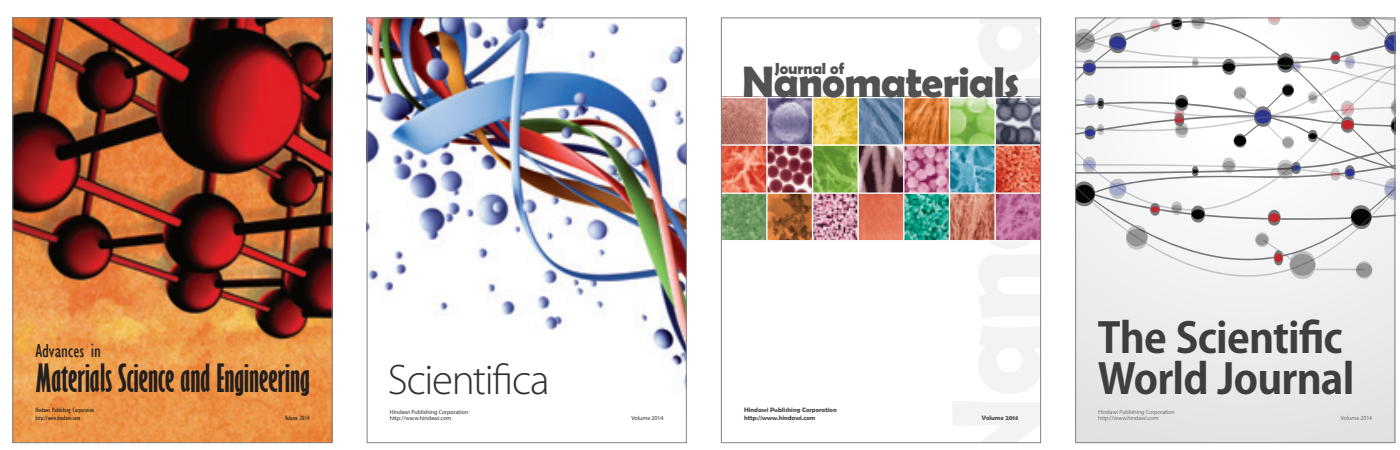

\section{The Scientific World Journal}
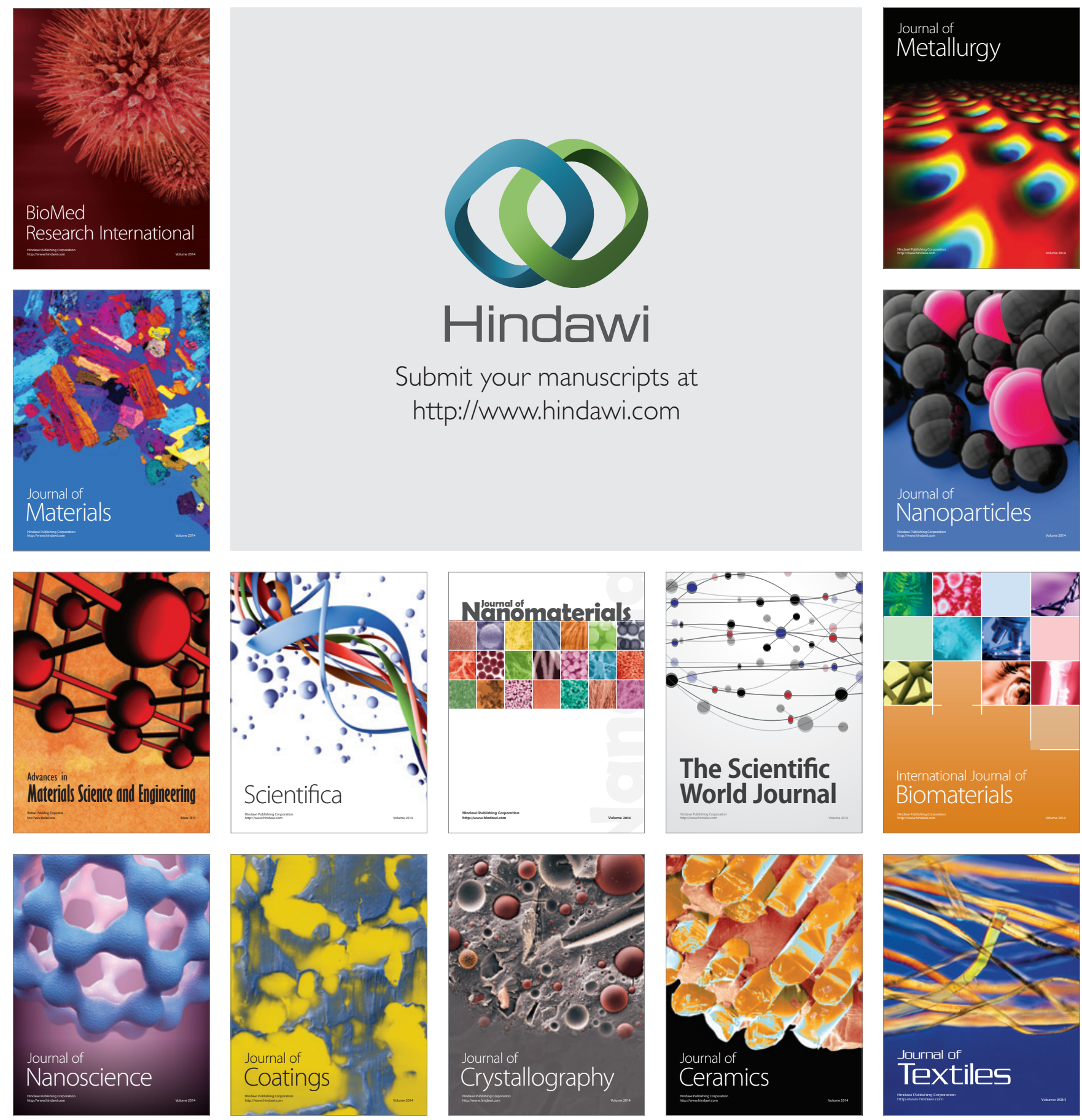